\title{
Child development surveillance: intervention study with nurses of the Family Health Strategy ${ }^{1}$
}

\author{
Altamira Pereira da Silva Reichert ${ }^{2}$ \\ Neusa Collet ${ }^{2}$ \\ Sophie Helena Eickmann ${ }^{3}$ \\ Marília de Carvalho Lima ${ }^{3}$
}

Objective: to evaluate the effectiveness of an educational action in child development surveillance performed by nurses working in primary health care. Methods: interventional study with a beforeand-after type of design, carried out with 45 nurses and 450 mothers of children under 2 years of age. Initially, it was evaluated the practices and knowledge of nurses on child development surveillance and the mothers were interviewed about these practices. Subsequently, workshops were carried out with nurses and four months later, the knowledge of nurses and the maternal information were reevaluated. Results: after intervention there was significant increase in the frequency of the following aspects: from $73 \%$ to $100 \%$, in relation to the practice of nurses of asking the opinion of mothers about their children's development; from $42 \%$ to $91 \%$, regarding the use of the systematized instrument of evaluation; from $91 \%$ to $100 \%$ with respect to guidance to mothers on how to stimulate child development. Conclusions: the intervention contributed to the increase of knowledge of nurses and implementation of child development surveillance, showing the importance of this initiative to improve the quality of child health care.

Descriptors: Child Development; Primary Health Care; Family Health; Pediatric Nursing.

\footnotetext{
'Paper extracted from doctoral dissertation "Vigilância do desenvolvimento neuropsicomotor de lactentes na estratégia de saúde da família", presented to Universidade Federal de Pernambuco, Recife, PE, Brazil. Supported by Conselho Nacional de Desenvolvimento Científico e Tecnológico (CNPq), Brazil, process \# 474322/2007-6.

2 PhD, Associate Professor, Departamento de Enfermagem de Saúde Pública e Psiquiatria, Universidade Federal da Paraíba, João Pessoa, PB, Brazil.

3 PhD, Associate Professor, Departamento Materno Infantil, Universidade Federal de Pernambuco, Recife, PE, Brazil.
}

Corresponding Author:

Altamira Pereira da Silva Reichert

Universidade Federal da Paraíba. Centro de Ciências da Saúde

Cidade Universitária

CEP: 58059-900, João Pessoa, PB, Brasil

E-mail: altareichert@gmail.com
Copyright (c) 2015 Revista Latino-Americana de Enfermagem This is an Open Access article distributed under the terms of the Creative Commons Attribution Non-Commercial License (CC BY-NC).

This license lets others distribute, remix, tweak, and build upon your work non-commercially, and although their new works must also acknowledge you and be non-commercial, they don't have to license their derivative works on the same terms. 


\section{Introduction}

The initial phase of life comprises a period of significant changes in the physical and neuropsychomotor development, requiring regular monitoring of children in order to detect early possible health problems. This monitoring, which is part of the activities on child development surveillance, should start from birth, since the first two years of life represent a significant period, and are ideal for interventions to prevent development problems $^{(1)}$.

The child development surveillance comprises all activities related to the promotion of normal development and detection of development problems, during the Primary Health Care (PHC) for the child. This is a continuous and flexible process, which involves information for health professionals, parents, teachers and others ${ }^{(2)}$.

In Brazil, the Ministry of Health established in 2004, strategic actions aiming at reducing child mortality. Among these actions is the child development surveillance, whose practice remains below expectations due to the lack of qualification of the nurses in performing this monitoring. In general, the nursing consultation in the PHC is focused on weight measurement, checking of the vaccination scheme and nutritional counseling. Therefore, deviations in the development are detected belatedly, by the time the child already has severe signs of impairment, making the treatment difficult, in most $\operatorname{cases}^{(3)}$.

The need to qualify the nurses to perform the child development surveillance is a priority, since many children who attend the health units of the PHC are at risk of developmental delay. Estimates of low-income countries suggest the use of educational media focused on improving the health of children and interventions with high-risk children and income transfer programmes, as interventions to promote early childhood development. Effective development investments in early childhood can reduce the inequalities perpetuated as a result of poverty, malnutrition and lack of access to education ${ }^{(4)}$.

Professional qualification by means of health education is considered of fundamental importance for carrying out the child development surveillance. This importance is due to the fragility of the care for children under two years of age, the impact of these actions on child health ${ }^{(5-6)}$ and the importance of health professionals understanding the needs and rights of children and their families in order to offer a humanized and quality attention(7). Therefore, this study aims to evaluate the effectiveness of an educational activity in child development surveillance, for nurses working in primary health care.

\section{Methods}

It is a quasi-experimental study, with a beforeand-after type of design and using the application of pre and post-test, in order to examine the effectiveness of the educational action of nurses. This action occurred as workshops on surveillance of the development of children under the age of two, for the 53 Family Health Teams (FHT) of the Sanitary District III (SD-III), in the city of João Pessoa, in the state of Paraíba - PB. The SD has a population of 180,000 inhabitants, and the FHT covers $90.5 \%$ of the households in this area.

The variables evaluated before and after the educational action were the knowledge of nurses on aspects of the child development surveillance, frequency of the child development surveillance in the nursing consultation and maternal information about the practices of nurses in the consultations of children under 2 years old.

The sample was initially comprised of all 53 nurses who worked in the Sanitary District III. However, after the workshops, in the second stage of the research, the final sample consisted of 45 nurses, as result of three refusals and five withdrawals. Regarding the maternal sample, for each nurse, five mothers were selected, totaling 225 mothers of children under two years of age in the first phase of the study, and other 225 in the second, totaling 450 mothers enrolled in the Health Family Units of such District. The five pairs of mothers/ children were selected randomly, after care in nursing consultation, as they were attended in the Family Health Unit.

The first step of the data collection was the application of a pre-test for evaluation of the nurses' actions regarding the child development surveillance. This evaluation was conducted before the participation of nurses in the workshop on child development surveillance, by means of an instrument with closed questions. These questions aimed to investigate the monitoring of neuropsychomotor development; if the nurse asked the opinion of the mother on the child development; if the nurse performed routine development evaluation and the frequency of this evaluation; if the nurse used a systematized instrument for assessing the development and if the nurse guided the mother on how to stimulate child development. For the application of this instrument, a convenient time was 
scheduled in the Family Health Unit, so that the nurses could complete the questionnaire, without interruption.

At this stage, mothers were also interviewed on developmental surveillance practices, carried out by nurses. The interviewees occurred at the FHU in the days scheduled for nursing consultation, immediately after the care of children by the nurse. This interview aimed to verify the attitude of the professional on that service, regarding the child development surveillance. The instrument applied to mothers questioned whether the nurse had evaluated the development of children during consultation and if the nurse guided her on how to stimulate the development of her child at home.

In the second stage, it was carried out the assessment of knowledge of nurses about child development at the time of the intervention. The questionnaire for evaluation of the knowledge of the nurses on child development contained 13 multiple choice questions, on milestones in the development of motor skills, language, personal-social and cognitive and the main risk factors for developmental delay. This questionnaire was applied before the workshop, i.e., before they have contact with the content addressed in the course and collected immediately after its filling.

Regarding the intervention, the workshop content on Child Development Surveillance was based on a manual published by PAHO in $2005^{(5)}$, and included in the content of the course named Integrated Management of Childhood Illness (IMCI).

The educational intervention took place from November 2008 to April 2009. In the first two months, there were three workshops on child development surveillance, in the context of the IMCI, each with a course load of 16 hours distributed in two days, with an average of 15 participants. The activities were theoretical and practical, considering that learning of IMCI strategy involves the ability of students' understanding and use of what they learned in practice ${ }^{(8)}$.

The theoretical activities were developed using active methodologies, with questioning as a teaching and learning strategy and aiming at raising awareness and encouraging nurses for the child development surveillance. The teaching method of the workshops had as principle the Meaningful Learning Theory of Ausubel, which states that the content is related to the previous knowledge of the individuals, requiring from them a favorable attitude, which gives specific meaning to the content assimilated by them ${ }^{(9)}$.

The post-test was applied four months after the workshops, with the same instruments initially used, consequently, the nurses had their knowledge and practices reassessed, and the mothers with children under two years of age were also randomly selected and interviewed.

The questionnaires were reviewed regarding their completing consistency and typed in double input, for the typing validation, using the Epi-Info software, version 6.04 .

The statistical analyzes were performed by using this program and the Statistical Package for the Social Sciences, version 12. The Chi-square test was used to check the association among the categorical variables and the $t$ test for the paired samples, to compare the average score of the correct answers related to the knowledge of nurses about child development, before and after intervention. It was adopted $P$ value $\leq 0.05$ as statistically significant.

The research project was approved by the Committee of Ethics in Research of the Center of Health Sciences of the Federal University of Paraíba, under protocol number 0216, and by the health education management of the city of João Pessoa. Nurses and mothers were informed on the research objectives and asked to sign the Informed Consent Form.

\section{Results}

Of the 45 nurses who participated in this study, all were female, predominantly aged between 41 and 50 years $(42.2 \%)$, followed by the group aged between 30 and 40 years $(28.9 \%)$. In relation to professional practice time, about half worked for 10 to 21 years, and the time of work in the FHS ranged between five and nine years $(75.6 \%)$, coinciding with the period when there was expansion of family health teams in the city of João Pessoa.

It is found that sociodemographic characteristics presented in Table 1 were similar in the group of participating mothers before and after intervention. In general, it is observed that families had low socioeconomic status, since around $70 \%$ had monthly family income of up to half a minimum wage per capita; however, half of the sample had 9 to 11 years of study. Regarding the number of residents in the household, in almost half of the sample, the families had four to five people, with a predominance of families with only one child. There was a significant difference only regarding the age of the children before and after the intervention, especially in the age group between 7 and 12 months. 
Table 1 - Socio-demographic characteristics of the family, maternal reproductive characteristics and biological characteristics of children before and after intervention. João Pessoa, PB, Brazil, 2009

\begin{tabular}{|c|c|c|c|c|c|}
\hline \multirow{3}{*}{ Variables } & \multicolumn{4}{|c|}{ Intervention } & \multirow{3}{*}{ p } \\
\hline & \multicolumn{2}{|c|}{ Before $(n=225)$} & \multicolumn{2}{|c|}{ After $(n=225)$} & \\
\hline & $\mathbf{n}$ & $\%$ & $\mathbf{n}$ & $\%$ & \\
\hline Monthly family income per capita $(\mathrm{MW})^{*}$ & & & & & 0.39 \\
\hline$\leq 0.25$ & 70 & 33.0 & 76 & 39.2 & \\
\hline 0.26 to 0.50 & 86 & 40.6 & 68 & 35.1 & \\
\hline$>0.50$ & 56 & 26.4 & 50 & 25.8 & \\
\hline Maternal education (years) & & & & & 0.45 \\
\hline 0 to 4 & 34 & 15.1 & 34 & 15.1 & \\
\hline 5 to 8 & 77 & 34.2 & 65 & 28.9 & \\
\hline 9 to 11 & 102 & 45.3 & 113 & 50.2 & \\
\hline 12 to 15 & 12 & 5.3 & 13 & 5.8 & \\
\hline Persons in the house & & & & & 0.22 \\
\hline 2 to 3 & 70 & 31.1 & 59 & 26.2 & \\
\hline 4 to 5 & 107 & 47.6 & 103 & 45.8 & \\
\hline 6 to 12 & 48 & 21.3 & 63 & 28.0 & \\
\hline Number of children & & & & & 0.87 \\
\hline 1 & 111 & 49.3 & 106 & 47.1 & \\
\hline 2 & 67 & 29.8 & 68 & 30.2 & \\
\hline 3 to 6 & 47 & 20.9 & 51 & 22.7 & \\
\hline Children aged $<5$ years in the house & & & & & 0.83 \\
\hline 1 & 164 & 72.9 & 167 & 74.2 & \\
\hline 2 to 4 & 61 & 27.1 & 58 & 25.8 & \\
\hline Child age (months) & & & & & 0.003 \\
\hline 1 to 6 & 111 & 49.3 & 89 & 39.6 & \\
\hline 7 to 12 & 54 & 24.0 & 88 & 39.1 & \\
\hline 13 to 24 & 60 & 26.7 & 48 & 21.3 & \\
\hline
\end{tabular}

MW - Minimum Wage $(1 \mathrm{MW}=\mathrm{R} \$ 465.00)$

* 13 records without information before and 31 after intervention.

Table 2 shows the items of the assessment of the knowledge of nurses on child development. The questions that showed an increase in the frequency of correct answers when comparing the pre-test results with the evaluation after the intervention were: the cause why a two months old child does not follow objects with his/her eyes, question on the assessment of motor development; and general knowledge about child development. Regarding the comparison of the mean score of the correct answers before and after the intervention, there was an increase from 7.3 to 8.5 , a statistically significant difference.

Table 3 shows the information provided by nurses about their developmental surveillance practices before and after the intervention. It is found that about $96 \%$ reported performing this type of consultation before the intervention, keeping the same percentage after the intervention; however, when asked about the routine evaluation of the development, these values were
$80 \%$ and $91 \%$, respectively. After educational action there was a significant increase in the frequency of the following aspects: from $73 \%$ to $100 \%$, on the practice of nurses of asking the opinion of mothers about the development of their children; from $42 \%$ to $91 \%$ for the use of a systematized instrument for the evaluation of development; from $91 \%$ to $100 \%$ with respect to guidance to mothers on how to stimulate their child development.

According to data presented in Table 4, it was verified a significant difference in the information provided by the mothers on developmental surveillance practices performed by nurses in the consultation of the child. After intervention, it was observed an increase in the frequencies regarding the action of these professionals of asking the opinion of the mothers on child development, and on performing developmental assessment and providing information to the mother on how to stimulate child development. 
Table 2 - Evaluation of knowledge of nurses on child development before and after intervention. João Pessoa, PB, Brazil, 2009

\begin{tabular}{|c|c|c|c|c|c|c|}
\hline \multirow{3}{*}{ Questions } & \multirow{3}{*}{ Successes } & \multicolumn{4}{|c|}{ Intervention } & \multirow{3}{*}{$\mathbf{P}$} \\
\hline & & \multicolumn{2}{|c|}{ Before $(n=45)$} & \multicolumn{2}{|c|}{ After $(n=45)$} & \\
\hline & & $\mathrm{n}$ & $\%$ & $\mathbf{n}$ & $\%$ & \\
\hline \multirow{2}{*}{$\begin{array}{l}\text { Causes why a two months old child does not follow } \\
\text { moving objects with his/her eyes }\end{array}$} & Yes & 27 & 60.0 & 39 & 86.7 & \multirow[t]{2}{*}{0.009} \\
\hline & No & 18 & 40.0 & 06 & 13.3 & \\
\hline \multirow[t]{2}{*}{ Age at which the child sit without support } & Yes & 38 & 84.4 & 30 & 66.7 & \multirow[t]{2}{*}{0.09} \\
\hline & No & 07 & 15.6 & 15 & 33.3 & \\
\hline \multirow[t]{2}{*}{ Age at which the child hearing is present } & Yes & 32 & 71.1 & 34 & 75.6 & \multirow[t]{2}{*}{0.81} \\
\hline & No & 13 & 28.9 & 11 & 24.4 & \\
\hline \multirow[t]{2}{*}{ Age at which the child develops language } & Yes & 28 & 62.2 & 33 & 73.3 & \multirow[t]{2}{*}{0.37} \\
\hline & No & 17 & 37.8 & 12 & 26.7 & \\
\hline \multirow[t]{2}{*}{ Knowledge about the motor development } & Yes & 10 & 22.2 & 25 & 55.6 & \multirow[t]{2}{*}{0.002} \\
\hline & No & 35 & 77.8 & 20 & 44.4 & \\
\hline \multirow[t]{2}{*}{ General knowledge of child development } & Yes & 22 & 48.9 & 33 & 73.3 & \multirow[t]{2}{*}{0.03} \\
\hline & No & 23 & 51.1 & 12 & 26.7 & \\
\hline \multirow[t]{2}{*}{ Risk factors related to neuropsychomotor deficit } & Yes & 36 & 80.0 & 37 & 82.2 & \multirow[t]{2}{*}{1.00} \\
\hline & No & 09 & 20.0 & 08 & 17.8 & \\
\hline \multirow[t]{2}{*}{ Identification of language delay } & Yes & 30 & 66.7 & 34 & 75.6 & \multirow[t]{2}{*}{0.49} \\
\hline & No & 15 & 33.3 & 11 & 24.4 & \\
\hline \multirow[t]{2}{*}{ Identification of skills expected for the age } & Yes & 29 & 64.4 & 32 & 71.1 & \multirow[t]{2}{*}{0.65} \\
\hline & No & 16 & 35.6 & 13 & 28.9 & \\
\hline \multirow[t]{2}{*}{ Knowledge about primitive reflexes } & Yes & 24 & 53.3 & 29 & 64.4 & \multirow[t]{2}{*}{0.39} \\
\hline & No & 21 & 46.7 & 16 & 35.6 & \\
\hline \multirow{2}{*}{$\begin{array}{l}\text { Identification of the command of the development } \\
\text { functions }\end{array}$} & Yes & 15 & 33.3 & 14 & 31.1 & \multirow[t]{2}{*}{1.00} \\
\hline & No & 30 & 66.7 & 31 & 68.9 & \\
\hline \multirow[t]{2}{*}{ Perception of child development } & Yes & 25 & 55.6 & 29 & 64.4 & \multirow[t]{2}{*}{0.52} \\
\hline & No & 20 & 44.4 & 16 & 35.6 & \\
\hline \multirow[t]{2}{*}{ General knowledge of motor skills } & Yes & 12 & 26.7 & 12 & 26.7 & 0.81 \\
\hline & No & 33 & 73.3 & 33 & 73.3 & \\
\hline Average of correct answers (SD) & & 7.3 & $(2.3)$ & 8.5 & (2.2) & $0.001^{*}$ \\
\hline
\end{tabular}

* Paired t-test

Table 3 - Information of nurses about child development surveillance practices before and after the intervention. João Pessoa, PB, Brazil, 2009

\begin{tabular}{|c|c|c|c|c|c|}
\hline \multirow{3}{*}{$\begin{array}{l}\text { Developmental surveillance } \\
\text { reported by the nurses }\end{array}$} & \multicolumn{4}{|c|}{ Intervention } & \multirow{3}{*}{$\mathbf{P}$} \\
\hline & \multicolumn{2}{|c|}{ Before $(n=45)$} & \multicolumn{2}{|c|}{ After $(n=45)$} & \\
\hline & $\mathbf{n}$ & $\%$ & $\mathbf{n}$ & $\%$ & \\
\hline \multicolumn{6}{|l|}{ Do you perform developmental surveillance consultation? } \\
\hline Yes & 43 & 95.6 & 44 & 97.8 & $1.00^{*}$ \\
\hline No & 2 & 4.4 & 1 & 2.2 & \\
\hline \multicolumn{6}{|l|}{ Do you do routine assessment of child development? } \\
\hline Yes & 36 & 80.0 & 41 & 91.1 & 0.23 \\
\hline No & 9 & 20.0 & 4 & 8.9 & \\
\hline \multicolumn{6}{|l|}{ Do you ask the mother's opinion about child development? } \\
\hline Yes & 33 & 73.3 & 45 & 100.0 & $<0.001$ \\
\hline No & 12 & 26.7 & 0 & 0 & \\
\hline \multicolumn{6}{|c|}{ Out of 10 children attended, how many have their development assessed? } \\
\hline 3 to 6 & 6 & 13.3 & 10 & 22.2 & 0.27 \\
\hline 7 to 9 & 8 & 17.8 & 5 & 11.1 & \\
\hline 10 & 22 & 48.9 & 26 & 57.8 & \\
\hline Do not evaluate the development & 9 & 20.0 & 4 & 8.9 & \\
\hline \multicolumn{6}{|l|}{ How do you assess the development? } \\
\hline Using only the knowledge & 17 & 37.8 & 0 & 0 & $<0.001$ \\
\hline
\end{tabular}


Table 3 - (continuation)

\begin{tabular}{|c|c|c|c|c|c|}
\hline \multirow{3}{*}{$\begin{array}{l}\text { Developmental surveillance } \\
\text { reported by the nurses }\end{array}$} & \multicolumn{4}{|c|}{ Intervention } & \multirow{3}{*}{$\mathbf{P}$} \\
\hline & \multicolumn{2}{|c|}{ Before $(n=45)$} & \multicolumn{2}{|c|}{ After $(n=45)$} & \\
\hline & $\mathrm{n}$ & $\%$ & $\mathrm{n}$ & $\%$ & \\
\hline Using systematized instrument & 19 & 42.2 & 41 & 91.1 & \\
\hline Do not evaluate the development & 9 & 20.0 & 4 & 8.9 & \\
\hline \multicolumn{6}{|c|}{ Do you guide the mother on how to stimulate child development? } \\
\hline Yes & 41 & 91.1 & 45 & 100.0 & $0.12^{*}$ \\
\hline No & 4 & 8.9 & 0 & 0 & \\
\hline
\end{tabular}

* Fisher's exact test

Table 4 - Maternal information about child development surveillance practices performed by nurses before and after intervention. João Pessoa, PB, Brazil, 2009

\begin{tabular}{|c|c|c|c|c|c|}
\hline \multirow{3}{*}{ Developmental surveillance reported by the mothers } & \multicolumn{4}{|c|}{ Intervention } & \multirow{3}{*}{$\mathbf{P}$} \\
\hline & \multicolumn{2}{|c|}{ Before $(n=225)$} & \multicolumn{2}{|c|}{ After $(n=225)$} & \\
\hline & $\mathbf{n}$ & $\%$ & $\mathbf{n}$ & $\%$ & \\
\hline \multicolumn{6}{|l|}{ Did you ask the mother's opinion about child development? } \\
\hline Yes & 53 & 23.6 & 132 & 58.7 & $<0.001$ \\
\hline No & 172 & 76.4 & 93 & 41.3 & \\
\hline \multicolumn{6}{|l|}{ Did you evaluate child development? } \\
\hline Yes & 108 & 48.0 & 178 & 79.1 & $<0.001$ \\
\hline No & 117 & 52.0 & 47 & 20.9 & \\
\hline \multicolumn{6}{|l|}{ Did you guide on how to stimulate child development? } \\
\hline Yes & 75 & 33.3 & 124 & 55.1 & $<0.001$ \\
\hline No & 150 & 66.7 & 101 & 44.9 & \\
\hline
\end{tabular}

\section{Discussion}

This study refers to an intervention related to the educational action performed by nurses on child development and practices concerning its surveillance, in order to improve the care for children in primary health care. By knowing of the workshops, nurses demonstrated great interest in participating in this activity, reporting insufficient knowledge on child development and recognizing its importance of improving the quality of care for children. Similar behavior was observed in a study with 192 pediatricians in Gujarat - India, where 92\% expressed interest in receiving training for assessment of child development, reporting little knowledge on development issues ${ }^{(10)}$.

The educational activities proposed in this study proved to be effective, considering that after the intervention, there was a significant increase of 1.2 points on the average of correct answers to the questions about developmental milestones. This result is consistent with a study carried out in Turkey, which found an increase in the average of the knowledge of doctors and nurses after training(11).
The results of a study carried out in Connecticut, United States, point to the same conclusion, by showing that intervention lead to change of professional practices by increasing the number of children identified with problems in neuropsychomotor development and referred for early intervention services ${ }^{(12)}$. Similarly, it was found in Jamaica that, after training, the professionals who assist children in the households incorporated the activities of promoting a health development in the primary care services, with consequent improvement in children development, as well as the increase of knowledge and the maternal practices in the care for the child(13).

By analyzing the results of each question used to evaluate the knowledge of the nurses about child development, it is clear that there was, mostly, an increase in the percentage of correct answers after the intervention. However, it was observed exception in the questions related to the age at which the child sits without support, identification of the command of development functions that must be evaluated during the consultation and general knowledge about motor skills. It is not known what hindered the retention of 
such knowledge, given that nurses had prior knowledge of the subject. It may be that the nurses did not evaluate these aspects in daily life, did not guide the mother or did not have affinity to this content, which makes the learning difficult. This, because according to the theory of Ausubel, so that the learning becomes meaningful, it is necessary that the individuals have previous knowledge about the subject, experience it and have the will to deepen $\mathrm{it}^{(8)}$.

In this research, it was observed contradictory answers of the nurses in relation to questions about routine practices of developmental surveillance in the consultations to the children, as most said performing this activity even before workshops. This information is probably overestimated, which was found when compared to maternal information, showing lower affirmative answers than those of nurses, especially before the educational activity. This attitude may occur because when questioned about their practices, the nurses realize the importance of the child development surveillance for the promotion of child health, realizing that they are not performing this practice satisfactorily, so they try to omit the gaps in professional action or they feel evaluated. Consequently, they report performing developmental surveillance at a frequency beyond reality.

Spite of that, in general, there was an increase in the frequency of the performance of developmental surveillance during routine consultations of childcare, confirmed by the responses of mothers. A Brazilian study on practices and knowledge in relation to the monitoring and child development surveillance, performed by pediatricians, in different regions of Brazil, showed worrying results and points out gaps, both in the formation of the pediatrician as in the clinical practice, since professionals have difficulty in recognizing risk factors and detecting changes of development, ensuring timely interventions ${ }^{(14)}$.

The opinion of the mothers about child development during consultation is fundamentally important for the anamnesis of neurodevelopment, because parental information is generally reliable and can help in the diagnosis of changes. If properly understood and valued by the professional, the opinions of the parents can lead to right decisions about the need for referral of children with development problems to early stimulation services $^{(15)}$. Therefore, mothers need to be considered as partners of the programme of prevention of disorders of child development(1), since the strengthening of competences for child care at this stage of life will lead to permanent benefits. In addition to the visual stimuli, auditory, olfactory, motors and those related to the interaction with adults, a study(16) stresses the importance of incorporation of caring and affection in the promotion of loving care, which strongly enhances the emotional, social, cultural and environmental aspects, aiming at reaching the full potential of the child.

The data also reveal that there was an increase in the use of a systematized instrument to evaluate the development of the children assisted by nurses participating in the research, and most of them have reported the use of this instrument after intervention. This practice is essential in childcare, because the use of a systematized instrument facilitates performing the child development surveillance. There might well be that the evaluation instrument has been used during the four months after the workshop; however, it is not predictable for how long it will be used, or whether it will be incorporated into childcare. This is because, even in countries in which the use of a systematized instrument for evaluating development is encouraged and standardized, professionals do not use it in all consultations.

There is a consensus among researchers on the importance of using a systematized instrument to evaluate the development of children during the consultations; otherwise, children with mild delays will no longer be detected due to the subtlety of signs. In the United States, the implementation of developmental surveillance and early detection of development problems have been limited in cases in which the professional does not use a systematized instrument or follow the protocols recommended by the American Academy of Pediatrics ${ }^{(17)}$.

It is considered as a positive aspect of this study, the fact that it has provided increase in knowledge and awareness of nurses to include the child development surveillance in their childcare practices, considering that 
most did not evaluate the psychomotor development before the intervention and presented lack of knowledge in this area. Almost all nurses of the Sanitary District III were trained, strengthening childcare consultation in that region. Another positive aspect was the participation of mothers, who acted confronting the information provided by the nurses.

On the other hand, a limitation of the study was the lack of a control group from another Health District, in which the educational action was not performed, evaluating only the knowledge and practices on child development surveillance, at two different times. However, the findings of this study were similar to those that have used control group (12-13,18).

\section{Conclusions}

This intervention promoted an increase in the knowledge of nurses on child development and frequency of evaluations in consultations to children under two years of age, contributing to the early detection of developmental changes. From the results, it is recommended the use of child development surveillance in the IMCI context, in the Family Health Strategy, because it is a fast application instrument and uses inexpensive material for detecting children with risk of development changes. It is also highlighted the need to use educational technologies aiming at overcoming weaknesses in the practice of the nurses, especially those working in primary health care for children.

\section{Acknowledgments}

To the mothers and nurses participating in the study and the staff of the Health District III.

\section{References}

1. Olusanya BO. Priorities for early childhood development in low-income countries. J Dev Behav Pediatr. 2011;32(6):476-81.

2. Blair M, Hall D. From health surveillance to health promotion: the changing focus in preventive children's services. Arch Dis Child. 2006;91(9):730-5.
3. Rugolo LMSS. Importância da monitorização do desenvolvimento em recém-nascidos prematuros. Rev Paul Pediatr. 2012;30(4):460-1.

4. Engle $\mathrm{PL}$, Fernald LCH, Alderman H, Behrman J, O'Gara C, Yousafzai A, et al. Strategies for reducing inequalities and improving developmental outcomes for young children in low-income and middle-income countries. Lancet. 2011;378(9799):1339-53.

5. Figueiras AC, Souza ICN, Rios VG, Benguigui Y. Organização Panamericana de Saúde. Manual de vigilância do desenvolvimento infantil no contexto da AIDPI. Washington, DC: OPAS; 2005.

6. Ribeiro DG, Pedrosa GB, Padovani FHP. Fatores de risco para o desenvolvimento de crianças atendidas em Unidades de Saúde da Família, ao final do primeiro ano de vida: aspectos sociodemográficos e de saúde mental materna. Ciênc Saúde Coletiva. 2014; 19(1):215-26.

7. Paranhos VD, Pina JC, Mello DF. Integrated management of childhood illness with the focus on caregivers: an integrative literature review. Rev. LatinoAm. Enfermagem. 2011; 19(1):203-11.

8. Fujimori $\mathrm{E}$, Higuchi $\mathrm{CH}$, Cursino EG, Veríssimo MLOR, Borges ALV, Mello DF, et al. Teaching of the Integrated Management of Childhood Illness strategy in undergraduate nursing programs. Rev Latino-Am Enferm [online]. 2013; 21(3):655-62.

9. Gomes AP, Dias-Coelho UC, Cavalheiro PO, Gonçalvez CAN, Rôças G, Siqueira-Batista R. The Medical education between maps and anchors: David Ausubel meaningful learning, the quest for the Lost Ark. Rev Bras Educ Med. 2008;32(1):105-11.

10. Desai PP, Mohite P. An exploratory study of early intervention in Gujarat State, India: pediatricians' perspectives. J Dev Behav Pediatr. 2011;32(1):69-74.

11. Ertem IO, Pekcici EBB, Gok CG, Ozbas S, Ozcebe H, Beyazova U. Addressing early childhood development in primary health care: experience from a middle-income country. J Dev Behav Pediatr. 2009;30(4):319-26.

12. McKay K. Evaluating model programs to support dissemination. An evaluation of strengthening the developmental surveillance and referral practices of child health providers. J Dev Behav Pediatr. 2006;27(1 Suppl):S26-9.

13. Powell C, Baker-Henningham H, Walker S, Gernay

J, Grantham-McGregor S. Feasibility of integrating 
early stimulation into primary care for undernourished Jamaican children: cluster randomised controlled trial.

BMJ. 2004;329(7457):89.

14. Zeppone SC, Volpon LC, Del Ciampo LA. Monitoring of child development held in Brazil. Rev paul pediatr [online]. 2012;30(4):594-9.

15. Glascoe FP. Evidence-based approach to developmental and behavioral surveillance using parents' concerns. Child Care Health Dev. 2000;26(2):137-49.

16. Oliveira AAP, Moreira RL, Pecora RAF, Chiesa AM. Relevant themes for child development training: a case study in light of health promotion. Rev Med. 2013;92(2):113-8.

17. American Academy of Pediatrics. Council on Children with Diabilities. Section on Developmental Behavioral Pediatrics. Project advisory committee. Identifying infants and young algorithm for developmental surveillance and screening. Pediatrics. 2006;118(1):405-20.

18. Jee SH, Szilagyl M, Ovenshire C, Norton A, Conn A, Blumkin $A$, et al. Improved detection of developmental delays among young children in foster care. Pediatrics. $2010 ; 125(2): 282-9$. 